\title{
Understanding Necessity Entrepreneurship
}

\author{
A Reflection on Book Review: "Institutional Case Studies on Necessity Entrepreneurship"
}

\author{
Mohamad Buheji \\ Founder - International Institute of Inspiration Economy \\ E-mail: buhejim@gmail.com
}

Edited by: Jeremi Brewer \& Stephen Gibson, Published (2016)- Edward Elgar, ISBN:9781783472321

Received: June 1, 2018 Accepted: June 20, 2018 Published: June 21, 2018

doi:10.5296/iss.v6i1.13298 URL: http://dx.doi.org/10.5296/iss.v6i1.13298

\begin{abstract}
Necessity Entrepreneurship (NE) haven't been closely covered in literature, especially with the speed of development in the last half century and the influence on different socio-economic perspectives. In this book review paper NE is synthesised as a means for self-employment solution on demand. Services of necessity entrepreneurs' survival and their type of mindset are reviewed, along with their best practices. Brazil success as a model NE country is covered as an example of what can any country do to move people out of poverty through NE schemes.

Other NE schemes as: fall-back system, close mentorship and coaching are explored in this review to show their importance compared to financial support. The paper recommends clear transition programs of self-employment and self-reliance that goes beyond the government responsibility by calling for more involvement of private sector, NGOs and even religious organisations. Further, book future improvements are suggested to give this book more shining role towards this highly important subject.
\end{abstract}

Keywords: necessity entrepreneurship, innovation, inspiration economy, youth economy, resilience economy 


\section{Introduction}

The urge for this book review is part of its title that focuses on the most neglected entrepreneurs in the world, i.e. those that come to entrepreneurship out of necessity. However, the uniqueness of this work come mainly due to its ability to address the unemployment issue in a more positive way, with suggestions that ease the transition of many populations of the society to self-employment. This work was followed by many thinking tanks such the Stanford University team Fairlie and Fossen (2017) study.

The Brewer and Gibson (2016) work shows how the self- employment helps to relieve the welfare system and promote the more efficient market. As a researcher, one could see the influence of this work cover many socio-economic perspectives that consider self-employment a solution for on-demand parenting, the ageing population, early retirement, youth economy, migration economy, etc. Thus this book is part of a roadmap that could be a cause for economic stability and quality of life development.

The work of Brewer and Gibson (2016) show that the culture and spirit of striving towards entrepreneurship lead always to positive results in a country socio-economic development, even from those who fail in becoming self-employed. As the book shows that even those who fail while attempting entrepreneurship out of necessity become usually more competent if they decided to be re-employed.

\section{Defining Necessity Entrepreneurship}

Most of the known definitions of 'entrepreneurship' are based on the observations of practices of opportunity entrepreneurs (OEs), i.e. those who started their business when they spot an opportunity in the market. Necessity Entrepreneurship (NE) is about the different type of people. It is about entrepreneurs who started their businesses when they could not find another means of living or employment. Such type of entrepreneurship is very important to developing and emerging economies. With the increase of instability in socio-economic condition, $\mathrm{NE}$ initiatives are growing faster than the mature OEs. It is estimated that one billion individuals in both developed and developing nations have no stable income or any viable options but to start a small NE activity.

\section{Services of Necessity Entrepreneurs Survival}

The editors of the book review presents variety of approaches for NE's. There are the start-up support programs as matching the unemployment allowance, or special mentoring or companionship programs or social insurance program. Also, there are the transformation programs from loan to grants in certain countries till the entrepreneurs reach the safe zone.

Another NE's service that came from Harvard University is Entrepreneurship Finance Lab (EFL's) that was developed to ease the disbursement of loans for developing countries. However, one can't see how EFL is dedicated for the NEs, specially that it uses psychometrics for loans risk assessment which actually is opposite of the idea of easing the loans of the start-ups and microstate where risk is very high yet even for low amount of loan. EFL's would be a best practice if it ensures the high accessibility for those in need and not 
only the speed of loan approval. Therefore, one could argue that an EFL's service should address the variety of necessity entrepreneurial cases as migrants, house wives, elderly, etc.

\section{Entrepreneurial Mindset}

Even though one could agree for importance of the financial support that both Brewer and Gibson (2016) for any entrepreneurship start-up, the book on the other hand fail to study or review or explore the importance of entrepreneurial mindset, spirit and idea, despite its importance to the theme of the book.

\section{Best Practices in Necessity Entrepreneurship Support Services}

"Institutional Case Studies On Necessity Entrepreneurship" carries lots of scattered best practices and success stories that could meet the requirement of inspiration economy for an independent business model with high autonomy for governance and survival. Buheji (2017a). This can be seen in the Greek experience in diversifying their entrepreneurship programs by customising them based on: the gender "Unemployed woman from 22-64", or "Young people", Educated "Young Scientists", or "Multi-member Families", or based on Geographic location that is designed to "Decentralise the Entrepreneurship Program" from the main city. Some of these ideas complement the recent work on the "Handbook of Youth Economy" in Buheji (2018a) where different employment solutions or initiatives were discussed to overcome the gap in the coming generation necessity entrepreneurship programs.

Another best practice model can be seen also in the USA minority focus on entrepreneurship programs that help to develop and accelerate the different minorities. It is also similar to the Indian program for disadvantaged youth such as the Bharatiya Yuva Shakti Trust (BYST) which address exactly the book theme. The success of BYST can be referred to the measures taken to see identify and monitor the amount of people employed by those youths who got the loan \& mentorship, which today at a record rate of 1:10. i.e. each one young entrepreneur is employing ten others.

The book also brings in the story of Lakshimi Venkatesan (resembling prince Charles program in UK) comes also from India. The story shows how NGO's can help necessity entrepreneurs succeed. It is similar to work carried and published under the International Inspirational Economy Project (IIEP) which works with school dropouts, or low performing students program. However, Lakshimi and her team teach us more innovative techniques for sustainability through the mentorship clinics both (mobile one or in case of emergency), Buheji (2018a).

\section{Women as part of Necessity Entrepreneurs}

One the strengths of the book is the focus on the minorities or where equalities need to be empowered. The Prospera is a Mexican case for microenterprise among women necessity entrepreneurs that deliver support to empower female-led micro-businesses through promoting more their civic engagement, with very low budgets. Such programs support local economies and inspire Mexican to support their local community economy. The uniqueness of the Prospera's program is that it is have many simple yet important learning steps for many 
decision makers, strategic planner, economists, etc. The case focusses and measures on social change that can be achieved due to NEs selective efforts for specific gender or demographics. The Prospera have many schemes as "Learn and Prosper", "Be responsible and Prosper" and "Share and Prosper" through using the following inspiration formula: (Empowerment with Tools + Market Linkages+ Civic Engagement).

\section{Necessity Entrepreneurs Fall-back System}

The NE fall-back system is only available in limited countries in the world and still it is under debate by many researchers and practitioners. However, this book show how leading countries as Switzerland and Austria have managed to establish fall-back system for NEs that give them the assurance of their ability to fall back safely and automatically to the social-welfare programs, if they couldn't continue their entrepreneurial start-up. This case could really be a special line for future studies as a way of building entrepreneurial spirit for the unemployed. This program is highly needed in developing countries where there is high unemployment of young generations who finish higher education. Thus if youth are promised to come back in the social welfare system if they fail in their businesses this would create a highly innovative youth economy environment where they would be willing to take risks to try and explore new possibilities which would revive the economy.

\section{Mentorship for Necessity Entrepreneurs}

Non-financial business support in many studies found to be of high importance and even surpass financial support in a different stages as many evidences have shown and specially in turbulent economies. Many start-ups and even anchor entrepreneurs need a type of mentorship to clear or codify the small gaps or the undeveloped business concept areas.

However, Brewer and Gibson (2016) don't clearly differentiate between mentorship of the classical entrepreneurial programs where most of the sponsors or business/start-ups incubators and accelerators would provide the professional training along with both general education and coaching or consulting and that mentorship of NEs. It could've been more interesting if the authors discussed the success stories of the NEs whom used the integrated three services in differentiated and delivered better results.

\section{NE Coaching Programs}

Many NEs need specific focused coaching besides mentorship programs. The Academy for Creating Enterprise (the Stephen W. Gibson project) in the Philippines is certainly a unique project where an isolated home is dedicated for support NEs youth in poverty areas where necessity entrepreneurial supervision is given to each entrepreneur till they become independent and create a turn in their life.

Another NEs coaching project is in Mexico. An academy that is blend mentorship and coaching with a variety of programs that target the residents and the night workers through a unique curriculum. The curriculum used by the academy is very useful for both the academics and practitioners as it gives a profound knowledge for NEs with each program target to tackle challenges for "Where there are no jobs?" 


\section{Macrothink \\ Issues in Social Science \\ ISSN 2329-521X \\ 2018, Vol. 6, No. 1}

\section{Banks for Necessity Entrepreneurs}

It could have been great if the editors explained in a chapter the type of necessities conditions that pull towards entrepreneurship. i.e. poverty, skills, family issues, unemployment, job dissatisfaction, etc. All these are reflected in stories inside the books, however, could've been great if abstracted at the beginning of the chapter.

\section{Avoiding the NE Free-Riders}

One would agree that any country's NE policies should avoid "free-rider" phenomena where loans are taken during the period of unemployment and the business plans are neglected once jobs are found. Therefore, it highly recommended that the feasibility studies should not be considered the only main pre-requisite for start-ups support.

\section{Supporting Transition from Unemployment to Self-Employment}

European and OECD countries emphasised in the last three decades on creating diversified paths that would ensure the best transformation from unemployment to self-employment. The results we have today a culture in these countries that believe in "small business" as a source of personal economic growth and employment prosperity.

OECD is working more on doing many projects that would enhance the probability of those transform to be self-employed once they have stayed in a long time as unemployed.

\section{Role of NGOs and Charity Organisation in establishing NEs Self-Reliance}

Using the bible "One heart one mind" with "no poor among them" the church of Latter-Day Saint established a self-reliance scheme that can be considered as a reference of excellent for many religious communities that should work on establishing resilience economy in their societies (Buheji, 2018b). The foresight of future in the church led to NEs dedicate employment workshops that target to build economically resilient follower and self-reliant community members. The idea of "Self-resilience centres" and its capacity assessment and income gap tools is similar the research latest work on "Breaking the Shield" that focused on the role of Humanitarian organisations in Bosnia to minimise those in poverty. Buheji and Ahmed (2017b).

\section{Brazil as a Model NE Country}

Despite different allegation of corruption claims on Brazil, this country deserves a praise for the amount of change it managed to bring to many poor communities with a record achievement and in short time. Brazil brought about $11 \%$ of the population out poverty due to focused programs as the NE's self-employment schemes. The Brazil program management team represented by SEBRAE deserve to be studied deeper. The design of their training program is comprehensive, but the most important for NE's is the rural empowerment and quality programs. 


\section{MlMacrothink}

\section{Areas for Future Improvement}

This book is full of best practices and surely it fits many readers with different backgrounds. However, the book gives too much emphasis on financial support rather than focusing on the utilisation and optimisation of the necessity entrepreneurship. The book goes through different details again as showing the different partnership programs for getting the funding which at sometimes found too boring and cause a loss of appreciation of the idea.

Discussing financial institutes as the Chinese "Hanhua Guarantee" is not appreciated due it is being out the scope of "necessity entrepreneurship". Yet one has to admit that there would be some learning about how should the banks in other developing countries deliver it services relevant to SME's.

In certain areas of the book loses the dedicated reader with the details and empty debate about the different countries bureaucratic policies in relevance to entrepreneurship. It is advised that such policies, the ones that are most relevant to the scope of the book, be summaries in a table, or in one or two pages. The length of the policies presented makes the book as a ledger or a listing of programs at a specific time than a thinking book and country management culture philosophy that is valid for many years. Therefore, this review would avoid the discussion about the programs structures, but would focus on the processes and the successful practices that managed to enhance the self-employment transformation.

Despite that the editors of the book were successful in putting important section titles, as for example, "single payment vs. recurring payment", or "provision of a fall-back solution"; when the paragraph is assessed it couldn't address the importance of the titles in both quality and size. These big and unique ideas could have opened lots of insights for the readers, if it was effectively explored and discsussed.

\section{Conclusion}

Despite the scattered information in this edited book, one can consider it as a ground-breaking book for NE focused studies. The book didn't cover lots of trends that would affect NE in the future, as for example "Sharing and Collaborative Economy", Buheji and Ahmed (2017).

Clearly, Brewer and Gibson (2016) show transition programs of self-employment and self-reliance that goes beyond the government responsibility and which closely involve other stakeholders of the community. The different stories in the book support the essence of "necessity entrepreneurship" which found to be very touching and even inspiring.

Further studies on 'Necessity Entrepreneurship' and how it has been or it can be associated with the creation and development, not only growth, of the communities are highly recommended. Countries strategic future foresight studies should include such important sustainability and resilient economy based concept. It is with these concepts we can only have hope for the future of our coming generations. 


\section{References}

Buheji, M. (2018a). Handbook of Youth Economy, AuthorHouse, UK.

Buheji, M. (2018b). Understanding the Power of Resilience Economy: An Inter-Disciplinary Perspective to Change the World Attitude to Socio-Economic Crisis, AuthorHouse, UK.

Buheji, M. (2017a). Inspiring GCC Family Business towards Lean Governance: A Comparative Study with Japanese. FB'S, V(7), 75-88.

Buheji, M., \& Ahmed, D (2017a). Review Paper - Creative Destruction and the Sharing Economy. International Journal of Youth Economy, 1(1), 119-120.

Buheji, M., \& Ahmed, D. (2017b). Breaking the Shield- Introduction to Inspiration Engineering: Philosophy, Practices and Success Stories, Archway Publishing, FROM SIMON \& SCHUSTER, USA.

Fairlie, R., \& Fossen, F. (2017). Opportunity versus Necessity Entrepreneurship: Two Components of Business Creation, SIEPR Discussion Paper No. 17-014, Stanford Institute for Public Policy Research. https://siepr.stanford.edu/sites/default/files/publications/17-014.pdf 